\title{
Assessment of Secondary Metabolites from Marine-Derived Fungi as Antioxidant
}

\author{
Nihad Abdel-Monem ${ }^{1}$, Ahmed M. Abdel-Azeem², E. S. H. El Ashry ${ }^{3}$, \\ Doaa A. Ghareeb ${ }^{1}$, Asmaa Nabil-Adam ${ }^{*}$ \\ ${ }^{1}$ Department of Biochemistry, Faculty of Science, Alexandria University, Alexandria, Egypt \\ ${ }^{2}$ Laboratory of Systemic Mycology, Department of Botany, Faculty of Science, Suez Canal University, Ismailia, Egypt \\ ${ }^{3}$ Department of Organic Chemistry, Faculty of Science, Alexandria University, Alexandria, Egypt \\ ${ }^{4}$ Marine Environmental Division, National Institute of Oceanography and Fisheries (NIOF) \\ Marine Biotechnology and Natural Product (MBNP), Alexandria, Egypt \\ Email: ${ }^{*}$ sama.biomarine@gmail.com
}

Received May 2, 2013; revised June 1, 2013; accepted June 15, 2013

Copyright (C) 2013 Nihad Abdel-Monem et al. This is an open access article distributed under the Creative Commons Attribution License, which permits unrestricted use, distribution, and reproduction in any medium, provided the original work is properly cited.

\begin{abstract}
Marine derived fungi are considered as a promising source of novel drugs due to their biodiversity and consequent chemo-diversity. Although marine microorganisms especially fungi are not well defined taxonomically, making this a promising frontier for the discovery of new medicines. This study focused on marine derived fungi as a model for bioactive exploration for new entities with anti-inflammatory and antioxidant capacity. Three in-vitro assays were used to investigate the bioactive antioxidant potentiality of fungal extracts. Thiobarbituric acid (TBARS), $\alpha, \alpha$-Diphenyl- $\beta$ picrylhydrazyl (DPPH) and NO assay are based on their total phenolic and flavonoid content of each extract group. Ch. globosum recorded the highest antioxidant activity (92.82\%) in TBARS assay, while $G$. dankaliensis came first by recording 59.28\% in DPPH assay in comparison with ascorbic acid (61.83\%). In NO inhibition assay, $N$. oryzae showed $49.3 \%$ comparing with ascorbic acid (73.12\%). From the preliminary result of our extracts, we can consider the marine derived fungi extracts as promising antioxidant and anti-inflammatory drug candidate.
\end{abstract}

Keywords: DPPH; TBARS; Marine Drugs; Marine Derived Fungi; Anti-Inflammatory; Antioxidant Capacity

\section{Introduction}

Reactive oxygen species (ROS) or free radicals may be designated as molecular sharks that damage molecules in cell membranes, mitochondria, DNA and are very unstable, tend to strip electrons from the molecules in the immediate surroundings in order to replace their own losses. Reactive oxygen species (ROS) is a collective term, which includes not only the oxygen radicals $\left(\mathrm{O}_{2} \bullet-\right.$, and - $\mathrm{OH})$ but also some non-radical derivatives of oxygen. These include hydrogen peroxide $\left(\mathrm{H}_{2} \mathrm{O}_{2}\right)$, hypochlorous acid $(\mathrm{HOCl})$ and ozone $\left(\mathrm{O}_{3}\right)[1]$.

ROS and free radical-initiated reactions are ascertained to play multiple roles in degenerative or pathological events such as aging, cancer, heart dysfunction and Alzheimer's disease [2]. Over about 100 disorders like rheumatoid arthritis, hemorrhagic shock, cardiovascular disorders, cystic fibrosis, metabolic disorders, neurodegenerative diseases, gastrointestinal ulcerogene-

${ }^{*}$ Corresponding author. sis and AIDS have been reported as ROS mediated [3].

The oxidative damage to DNA, proteins and other cellular determinants seems inevitable when the concentration of ROS exceed tolerability of cells.

The free radical nitric oxide (NO) is also a highly reactive free radical capable of mediating a multitude of reactions [4] NO, is an uncharged molecule containing an unpaired electron in its outermost orbital, allowing it to undergo several reactions functioning either as a weak oxidant (electron donor) or as an anti-oxidant (electron acceptor). Also, it is able to react with other inorganic molecules (i.e. oxygen, superoxide or transition metals), structures in DNA (pyrimidine bases), prosthetic groups (heme) or with proteins leading to S-nitrosylation of thiol groups, nitration of tyrosine residues or disruption of metal-sulfide clusters such as zinc-finger domains or ironsulfide complexes [5].

Moreover, free radicals are known to take part in lipid peroxidation in foods, which is responsible for rancid odors and flavors, which decrease the nutritional quality. 
Therefore, synthetic antioxidants such as butylated hydroxyanisole (BHA), butylated hydroxytoluene (BHT) and tert-butyhydro-quinone (TBHQ) are widely used in the food industry as potential inhibitors of lipid peroxidation. However, previous studies have demonstrated that BHA and BHT accumulate in the body and result in liver damage and carcinogenesis [6-9]. An inflammatory response implicates macrophages and neutrophils, which secrete a number of mediators (eicosinoids, oxidants, cytokine and lytic enzymes) responsible for initiation, progression and persistence of acute or chronic state of inflammation [10]. NO, along with superoxide $\left(\mathrm{O}_{2} \bullet-\right)$ and the products of their interaction, initiates a wide range of toxic oxidative reactions causing tissue injury [11].

The role of ROS/RNS in inflammation is clearly demonstrated by the anti-inflammatory effects of the antioxidants. Niric oxide synthase inhibitors are also effective as anti-inflammatory agents in carrageenan-induced rat paw odema method as SOD. These may be due to the removal of $\mathrm{O}_{2} \bullet-$ by SOD, so preventing $\mathrm{O}_{2} \bullet-$ dependent formation of a factor chemotactic for neutrophils [12].

Likewise, the neutrophils also produce oxidants and release granular constituents comprising of lytic enzymes performing important role in inflammatory injury [13]. Reactive oxygen intermediates (ROI) are believed to be mediators of inflammation and responsible for the pathogenesis of tissue destruction in rheumatoid arthritis [14].

The antioxidants could attenuate this oxidative damage of a tissue indirectly by increasing cells' natural defenses $[15,16]$, and/or directly by scavenging the free radical species [17]. In order to reduce the damage of ROS to the human body, antioxidants are commonly used in processed foods. Antioxidants could alleviate the oxidative damage of a tissue indirectly by increasing cells' natural defenses and directly by scavenging the free radical species $[9,16,17]$.

The potent biological activity of many marine natural products is of relevance for their ecological function but is also the basis of their biomedical importance [18]. As a slightly opened reservoir of special bio-resources, some marine microorganisms have demonstrated to be excellent producers of biologically active and/or structurally novel metabolites [19]. Marine organisms, particularly marine fungi, are well-known for their production of unique biologically active metabolites. Among marine fungi, those living in association with algae, represent a rich source of novel antioxidant products. The association between algae and fungi is called "Algicolous".

Antioxidants protect cells against the damaging effects of reactive oxygen species (singlet oxygen, superoxide, peroxyl radicals, hydroxyl radicals and peroxynitrite) and help us to fight diseases like artherosclerosis, dementia and cancer. In addition, they may be useful as therapeutics or food additives [20]. For that, the finding of new antioxidative leads (marine-derived fungi), which are capable of preventing and/or eliminating oxidative stress and the development of suitable screening bioassays merits, consequently, have high priority and would be very welcomed [21-23].

\section{Materials and Methods}

\subsection{Marine Sample}

Samples of honeycomb sponge (Hippospongia communis) were collected from the west coast of Alexandria to Libya borders (Sidi Krir area to El-Salloum by dragging ships). While, Ascidians samples (Styela canopus) and seaweeds samples were collected monthly from Anfoshi Bay as shown in Figure 1.

\subsubsection{Isolation of Sponge-Derived Fungi}

To get rid of nonspecific fungal propagules from seawater column on sponge and jellyfish surfaces, animal tissues were rinsed three times with sterile seawater. The surface of the sample was disinfected with $70 \%$ ethanol for 2 minutes. The inner tissue was taken out with a scalpel and forceps and then cut into small cubes approx. $0.5 \mathrm{~cm}^{3}$. A total of $15-20$ cubes of each sample were placed on isolation media.

All isolation and culture maintaining media for marine taxa were prepared by sea water (SW) and isolation media basically were supplemented with Rose bengal $(1 / 15,000)$ and chloramphenicol $(50 \mathrm{ppm})$ for suppression of bacterial growth. Five media were adopted for isolation after Atlas (2004) they were: Sea Water Rose bengal Chloramphenicol Agar (SWRCA), Sea Water Czapeks Yeast Extract Agar (SWCYA), Sea Water Oatmeal agar (SWOA), Sea Water Agar (SWA), and Sea Water Potato Dextrose Agar (SWPDA).

For maintaining cultures and for proper identification, pure cultures of isolated fungi were grown on standard media such as Vegetable Agar (V8), Oatmeal Agar (OA), Malt Extract Agar (MEA) Potato Dextrose Agar (PDA) and Potato Carrot Agar (PCA).

\subsubsection{Identification of Isolates}

Taxonomic identification using morphology characteristics of fungal isolates down to the species level on standard media was mainly based on the following identification keys: [24] Pitt (1980) [25] for Penicillium (on Czapek Yeast Extract Agar (CYA) \& Malt-Extract Agar (MEA)); Raper \& Fennell (1965) [26] for Aspergillus (on Czapek Agar (CZ)); Ellis (1971, 1976) [8,27] for dematiaceous hyphomycetes (Potato Carrot Agar (PCA)); Booth (1971) [29] for Fusarium (Potato Dextrose Agar (PDA)); Arx (1981) [30], Domsch et al. (2007) [31], 


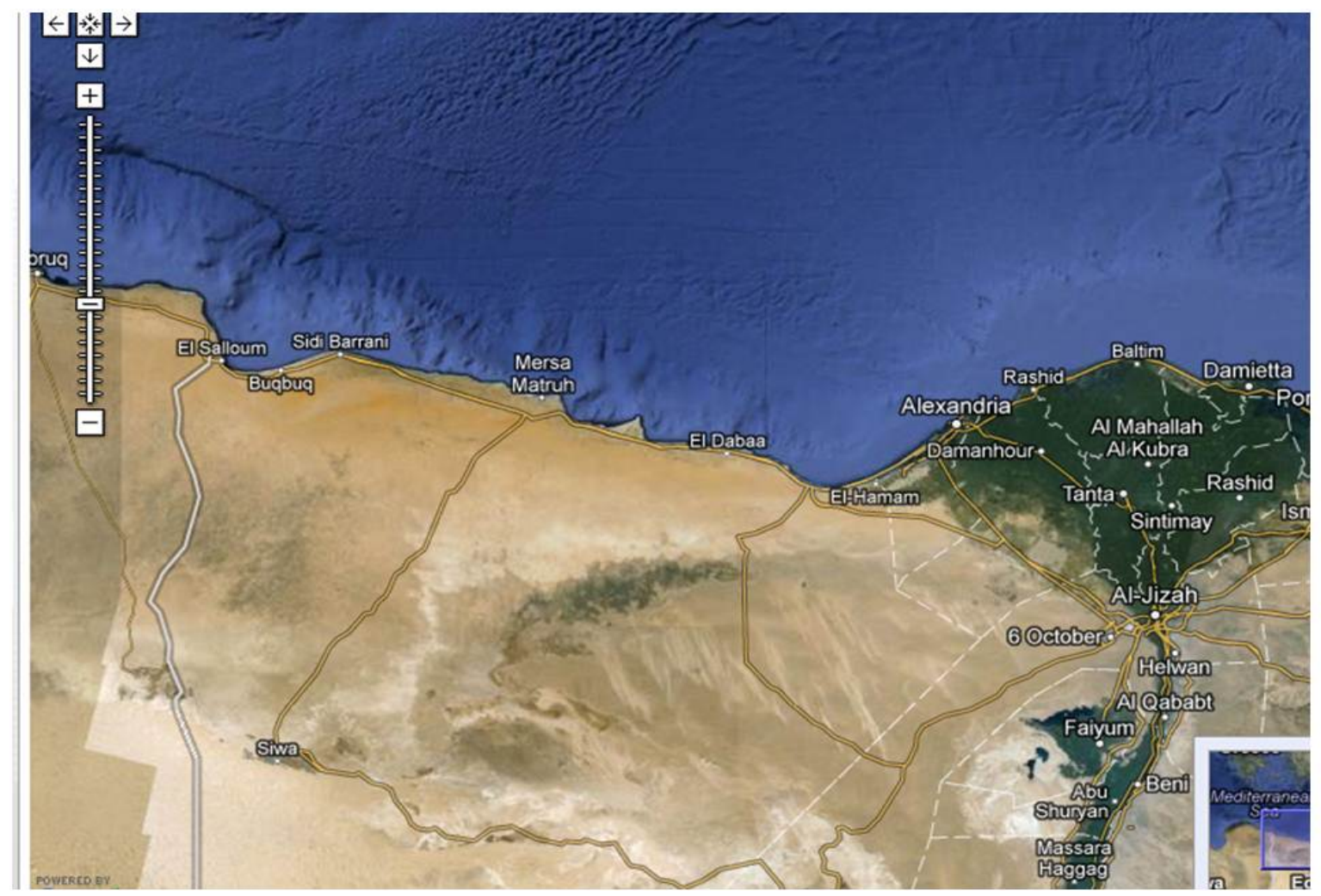

Figure 1. The location of sample collection.

Watanabe (2002) [32] for miscellaneous fungi (on MEA, PDA, CYA); Arx et al. (1986) [33] and Cannon (1986) [34] for Chaetomium (Oat Meal Agar + Lupin Stem (OA + LUP)). The systematic arrangement follows the latest system of classification appearing in the $10^{\text {th }}$ edition of Ainsworth and Bisby's Dictionary of the fungi (Kirk et al. 2008) [35] and Species Fungorum web site (http://www. speciesfungorum.org/Names/Names.asp).

\subsection{Preparation of Marine Fungus Extract}

Preparative-scale production $(0.5 \mathrm{~L})$ was carried out in 1 L Erlenmeyer flasks contained potato dextrose extract (Difco) for 2 weeks at $28^{\circ} \mathrm{C}$ in a shaking incubator at 102 rpm. Pellets were homogenized and centrifuged by using cooling centrifuge at $8000 \mathrm{rpm}$ for $2 \mathrm{~min}$ at $4^{\circ} \mathrm{C}$ Resultant mixtures were extracted with ethyl acetate $(1 \times 50$ $\mathrm{ml}$ ), the organic fractions were combined, and the solvent removed at reduced pressure and $35^{\circ} \mathrm{C}$. Residues were redissolved in DMSO for further bioassay. The steps of isolation and extraction of fungi and secondary metabolites are shown in Figure 2.

\subsection{Biochemical Profiling for Fungal Extract}

\subsubsection{Determination of Total Phenolic Content in Different Fungal Species Extracts}

Total phenolic compounds in the fungal extracts were determined by the method of Taga et al. (1984) [36].

\subsubsection{Determination of Total Flavonoid Content in Different Fungal Species Extracts}

Total flavonoid content was determined by a colorimetric method of Zhishen et al. (1999) [37].

\subsubsection{Diphenyle $\alpha$ - $\alpha$-Picrylhydrazyl (DPPH) Radical Scavenging Effect of Different Fungal Species Extracts}

DPPH radical scavenging assay of the total extract was performed by using modified previously established methodology by Blois (1958) [38] and Amarowicz et al. (2000) [39].

$\%$ scavenging $=[(\mathrm{A}$ control $-\mathrm{A}$ sample $] / \mathrm{A}$ control $\times$ 100

\subsubsection{Determination of Thiobarbituric Acid Reactive Substance Method Using TBARS Assay for Different Fungal Species Extracts}

The method used was adapted from Wallin et al. (1993) [40] and modified by Fisch (year).

$\%$ scavenging $=[(\mathrm{A}$ control $-\mathrm{A}$ sample $] / \mathrm{A}$ control $\times$ 100.

\subsubsection{Chromatography}

$20 \mu 1$ sample extract analyzed with an eclipsed XDB C18 


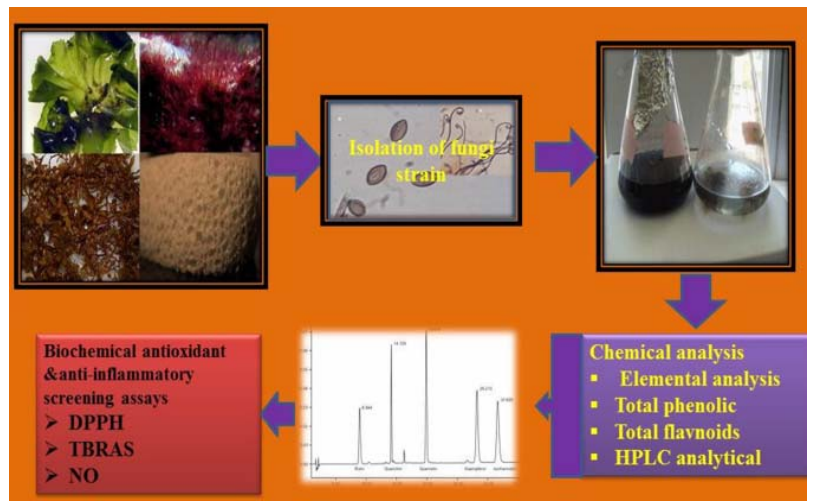

Figure 2. Summarize the production of secondary metabolites from marine derived fungi.

$(5 \mu \mathrm{m}, 4.6 \times 150 \mathrm{~mm})$ column using a mobile phase consisting $1 \%(\mathrm{v} / \mathrm{v})$ formic acid in aqueous solution: acetonitrile: 2-propanol (70:22:8), $\mathrm{pH} 2.5$; flow rate: 0.75 $\mathrm{ml} / \mathrm{min}$, temperature: $30^{\circ} \mathrm{C}$, UV detection at $320 \mathrm{~nm}$; Agilent technologies 1200 series [41].

\section{Result}

The total phenolic and flavnoids content in different fungal extracts.

The highest total phenolic content goes to $G$. dankaliensis while total flavnoids content the higher activity recorded belong to Engyodontium album.

\subsection{Result of Lipid Preoxidation Inhibition Using TBARS Assay in Different Fungal Extracts}

The higher activity in the inhibition of lipid preoxidation assay belongs to Chaetomium globosum and the lowest activity goes to $G$. dankaliensis.

\subsection{Chemical Composition in Different Fungal Extract}

The result of chemical copostion showed that G. dankaliensis and Trichurus spiralis had the highest sulfur ratio than the other three fungal extracts.

\subsection{Result of Antioxidant Capacity Using DPPH Assay in Different Fungal Extracts Comparing to Ascorbic Acids}

The result of total antioxidant by DPPH assay show that G. dankaliensis came first by recording $59.28 \%$ in DPPH $49.3 \%$ comparing with ascorbic acid (73.12\%).

\subsection{Result of NO Inhibition Assay in Different Fungal Extracts Comparing to Ascorbic Acids}

The result of total anti-inflammatory by NO assay show that C. globosum have the highest activity from $1 \mathrm{mg}$ concentration up to $5 \mathrm{mg}$,where at $6 \mathrm{mg}$ the highest activity goes to Nigrospora oryzae.

\subsection{Determination of Total Gallic Acid Content by HPLC}

The result of total gallic content in $10 \mathrm{mg}$ show that the highest concentrations belong to Engyodontium album. While gallic acid concentration in C. globosum at $10 \mathrm{mg}$ recorded zero content.

\section{Discussion}

In recent decades an increasing tendency towards the use of natural substances instead of synthetic ones has been obtain comparison to natural substances, it will take long time for them to complete their natural cycles and return to nature; thus causing a lot of environmental pollution. Also with the increase in the price of raw materials, the problem of cost benefits for chemical production is becoming more considerable. Natural antioxidants are ginning importance, due to their benefits for human health, decreasing the risk of degenerative diseases by reduction of oxidative stress and inhibition of macromolecular oxidation [42-44]. Their uses preserving food additives [45].

The antioxidant field receives increased interest and currently about 10,000 articles per year concern antioxidants of various kinds (ISI Web of Knowledge). Oxidation reactions are a major concern for the food industry, and antioxidants are widely needed to prevent oxidative changes in food. But the need for antioxidants for use in other oxidisable goods, such as cosmetics and pharmaceuticals is also on the rise.

Polyphenolic compounds are widely distributed in plant kingdom [46], reports indicate that there is a positive relation between total phenolic content and antioxidant activity in many plant species [47]. Phenolic compounds in plants are viewed as powerful in vitro antioxidants due to their ability to donate hydrogen or electrons and to form stable radical intermediates [48]. For small marine antioxidants novel discoveries are increasingly reported $[49,50]$. Interestingly, antioxidants found in terrestrial plants (catechin, gallic acid, catechol, morin, rutin) were reported present, inhibit reactive oxygen species (ROS) generation through anti-inflammatory effects [51], and that with agreement with our result as in Figureas 3-7 using DPPH assay as a model for oxidative stress our extracts show antioxidant activity with very low concentration range from $1 \mathrm{mg}$ to $6 \mathrm{mg}$, as well as scavenge free radicals as in Figures 8-11 as well as lipid preoxidation inhibition using TBARS inhibition model as in Figure 12 [51,52].

Our study show that high inhibition activity comparing 


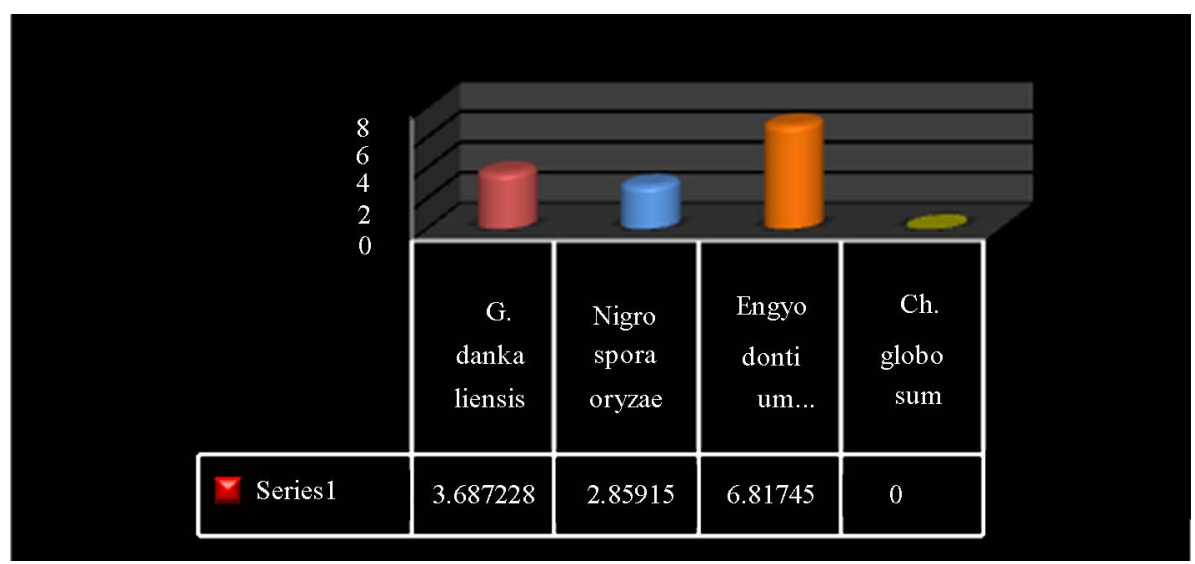

Figure 3. Show that the gallic acid content in different fungal extract by HPLC.

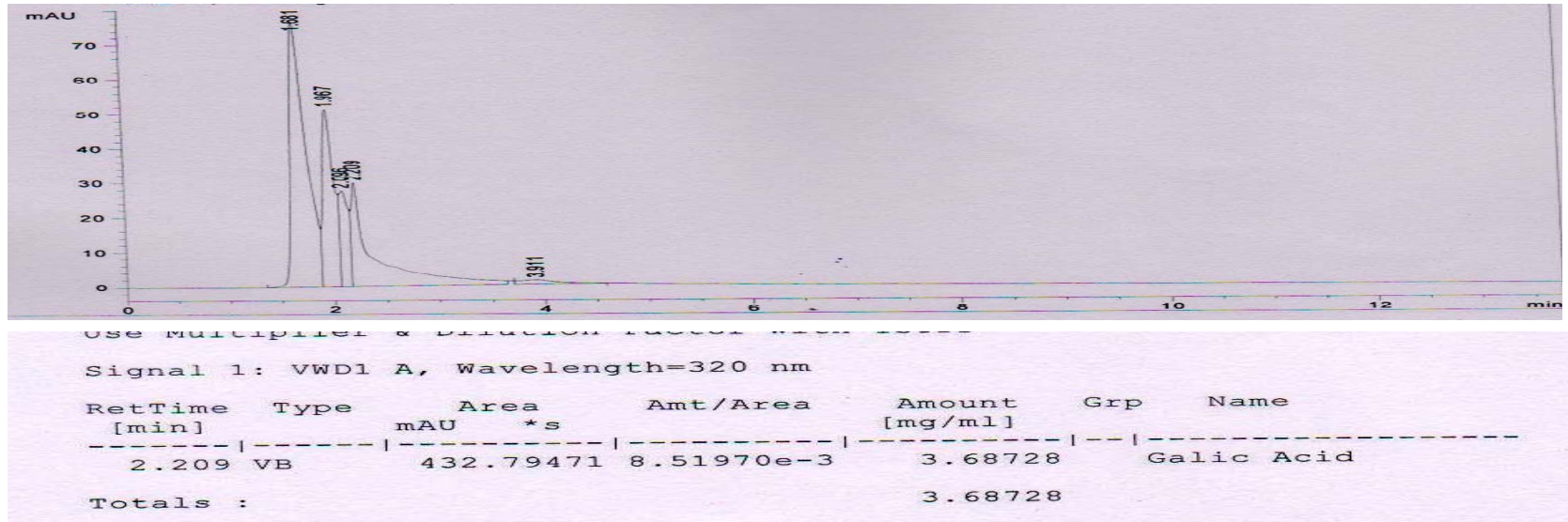

Figure 4. HPLC chromatogram shows the result of gallic acid in G. dankaliensis.
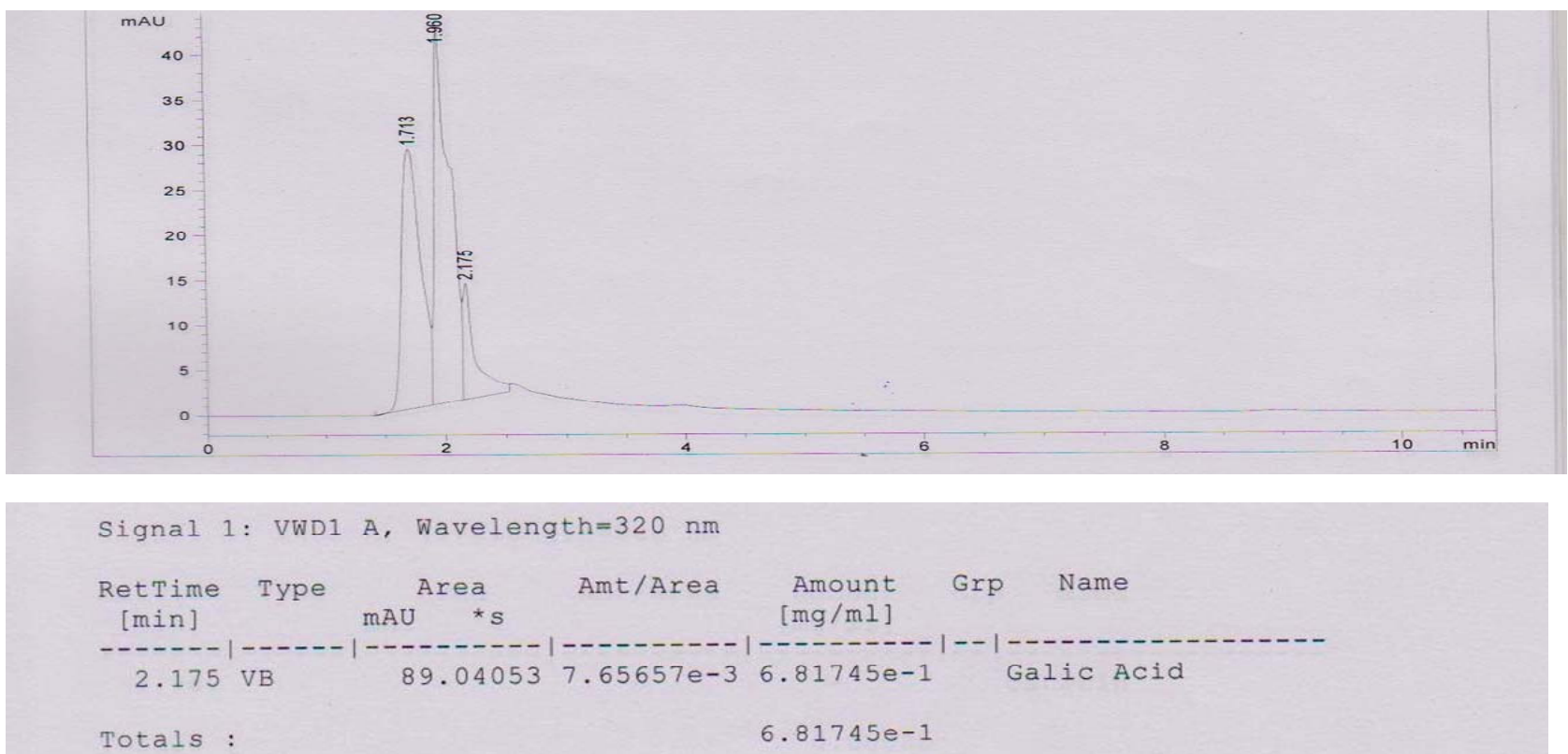

Figure 5. HPLC chromatogram shows the result of gallic acid in Nigrospora oryzae. 

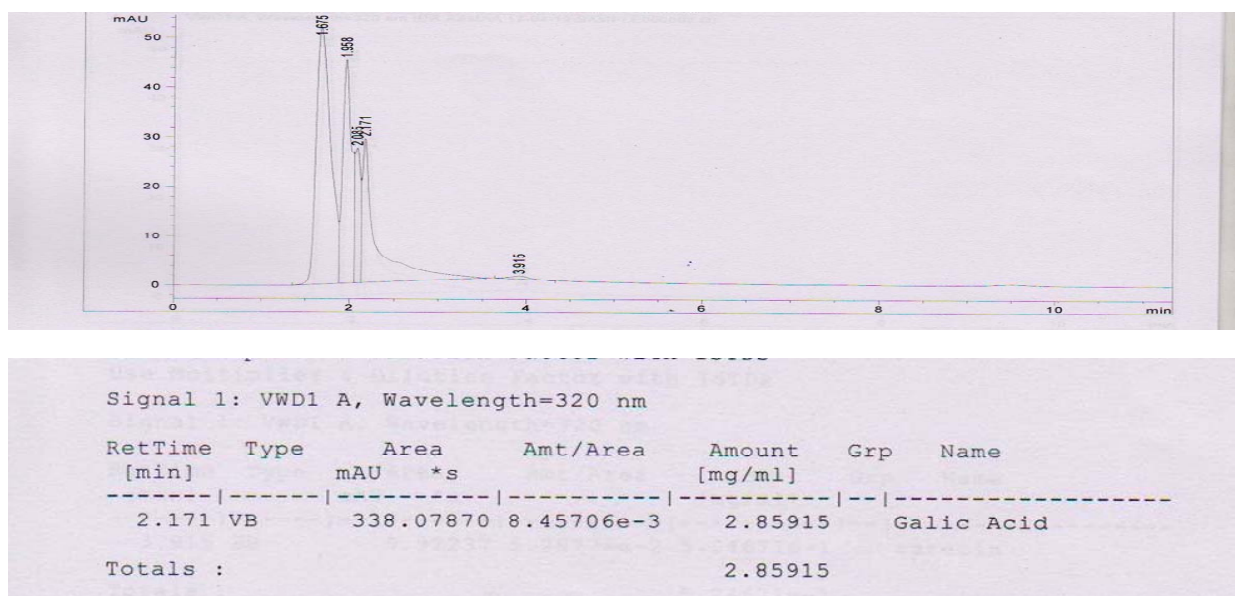

Figure 6. HPLC chromatogram shows the result of gallic acid in Engyodontium album.
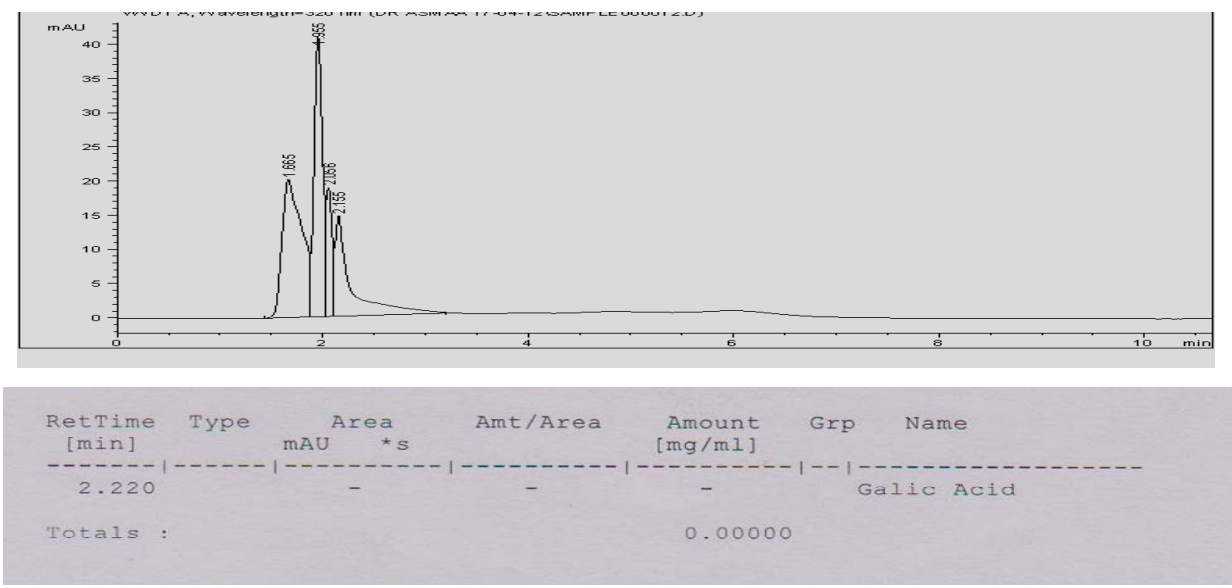

Figure 7. HPLC chromatogram shows the result of Gallic acid in Chaetomium globosum.

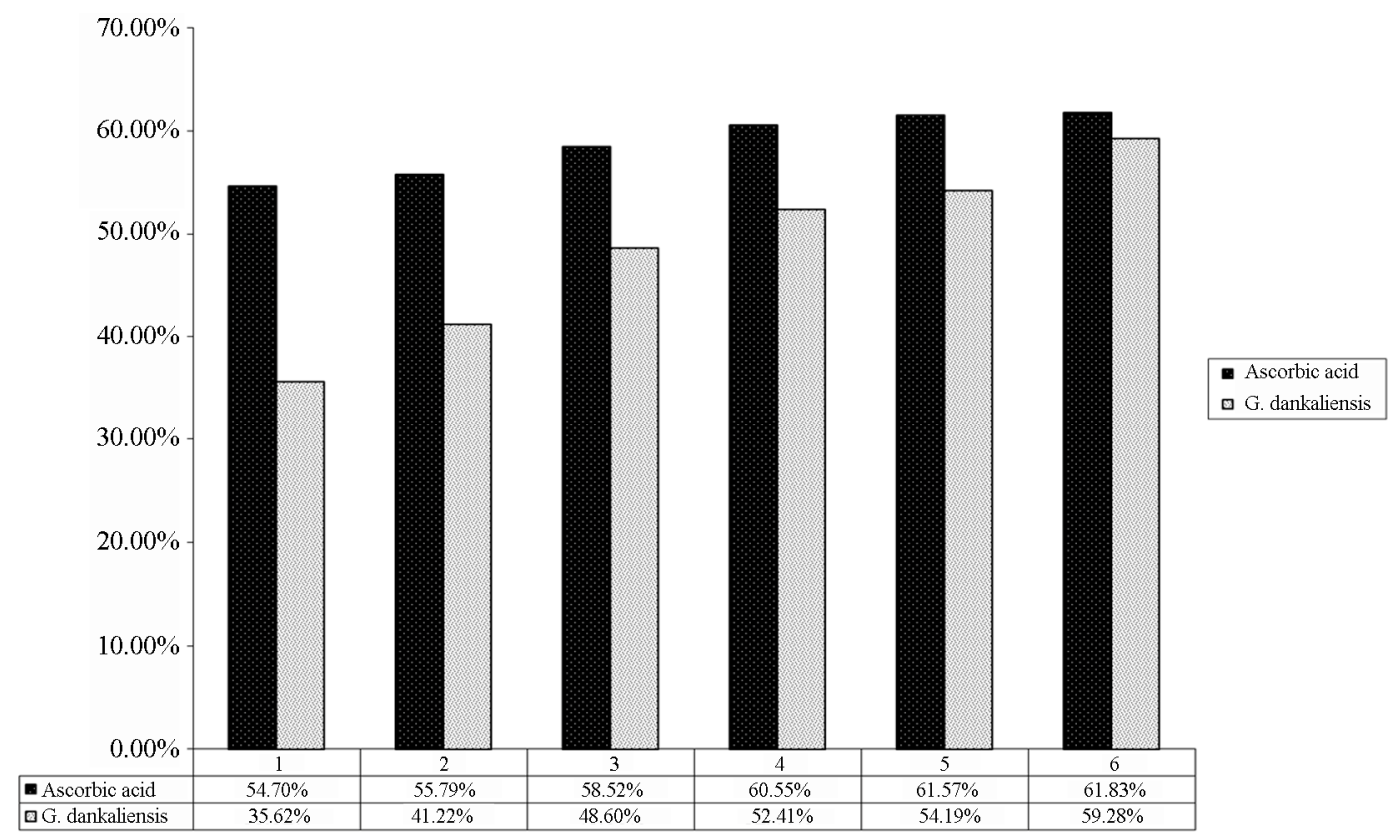

Figure 8. Show the DPPH inhibition assay by G. dankaliensis. 


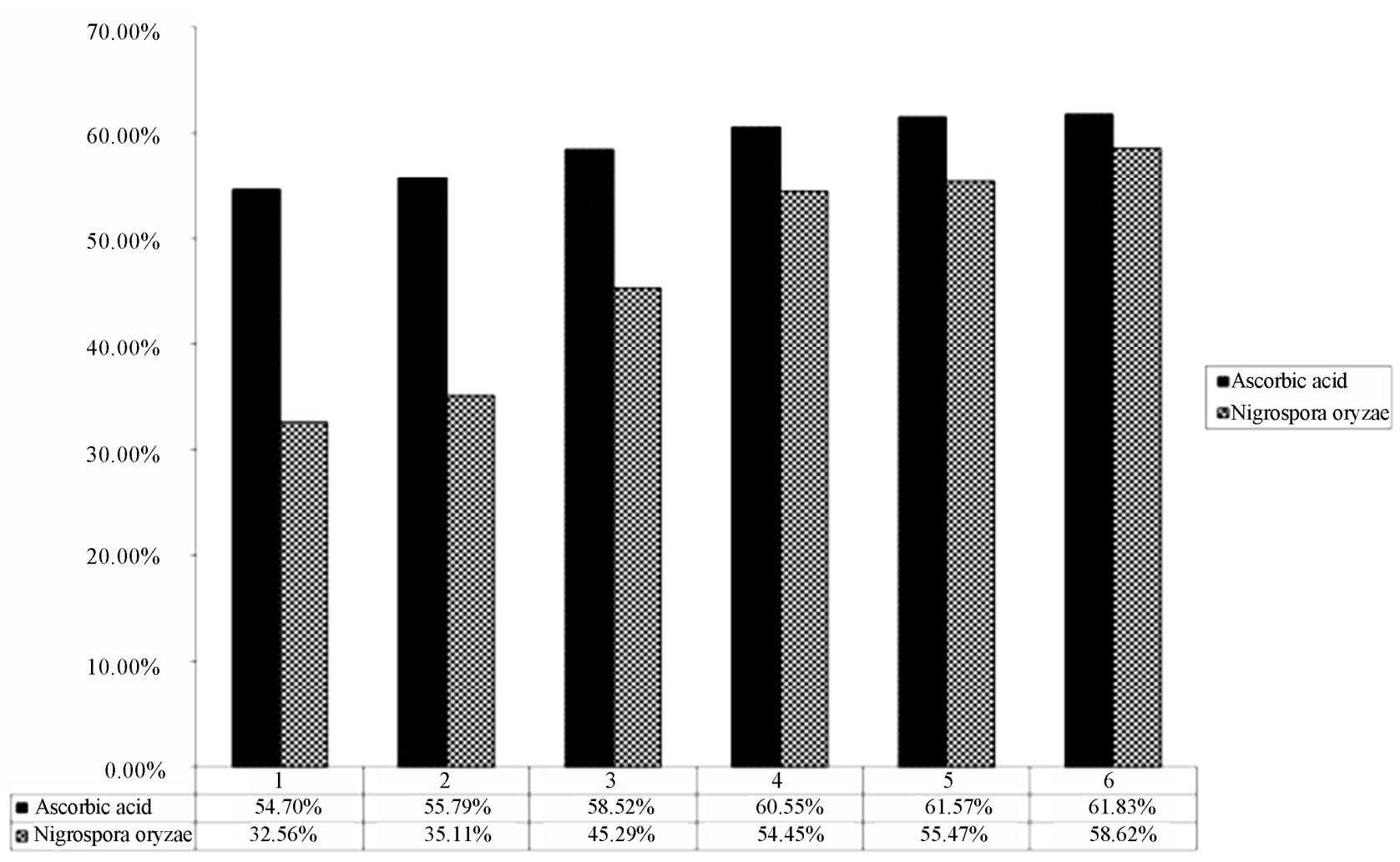

Figure 9. Show the DPPH inhibition assay by Nigrospora oryzae.

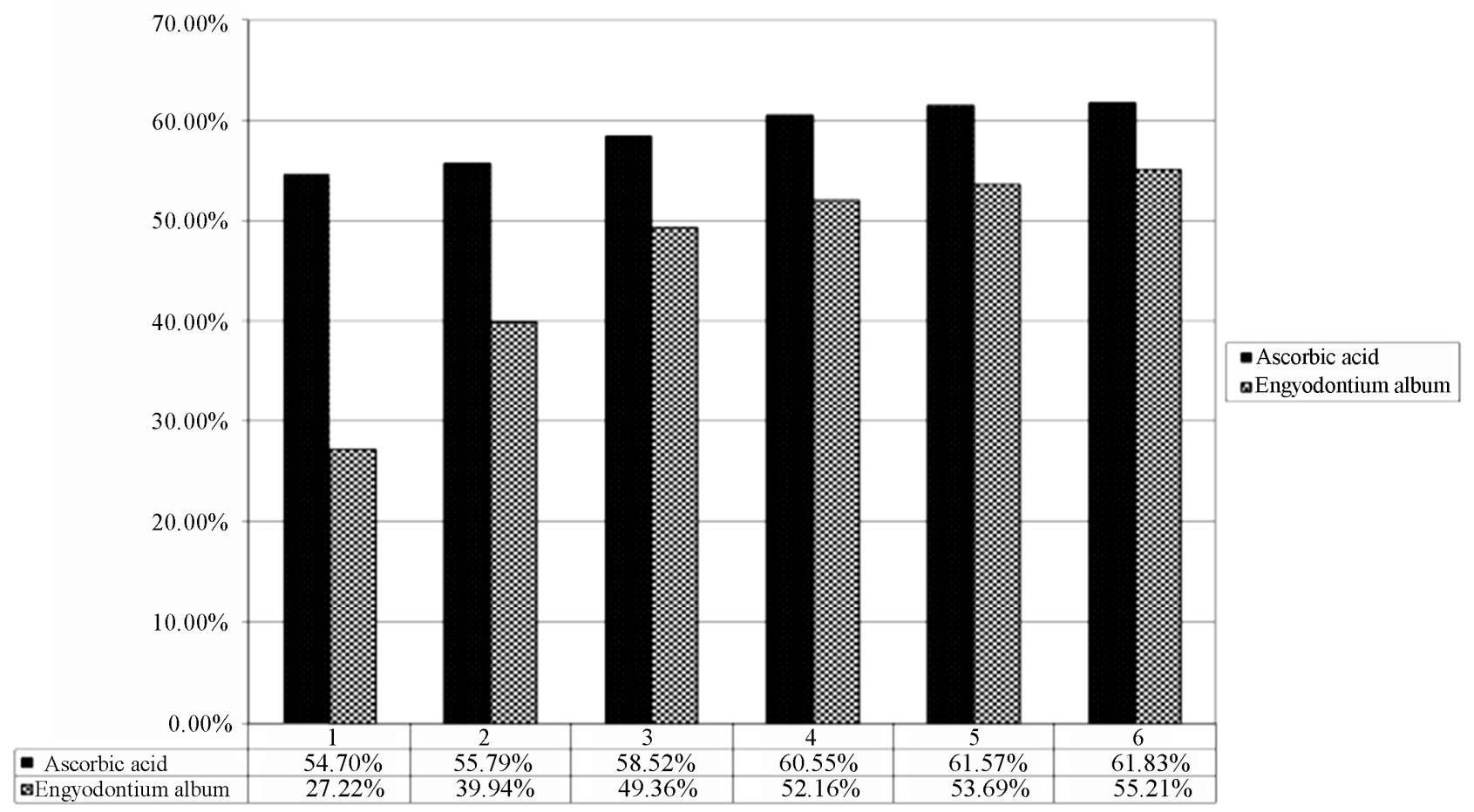

Figure 10. Show the DPPH inhibition assay by Engyodontium album.

with ascorbic acids and regard to low concentration used in our study, this activity may be attributed to the high content of total phenolic and flavnoids which act as ex- cellent antioxidant, as shown in Figures 13 and 14. where the best-described property of almost every group of flavonoids is their capacity to act as antioxidants. Flavonoids 


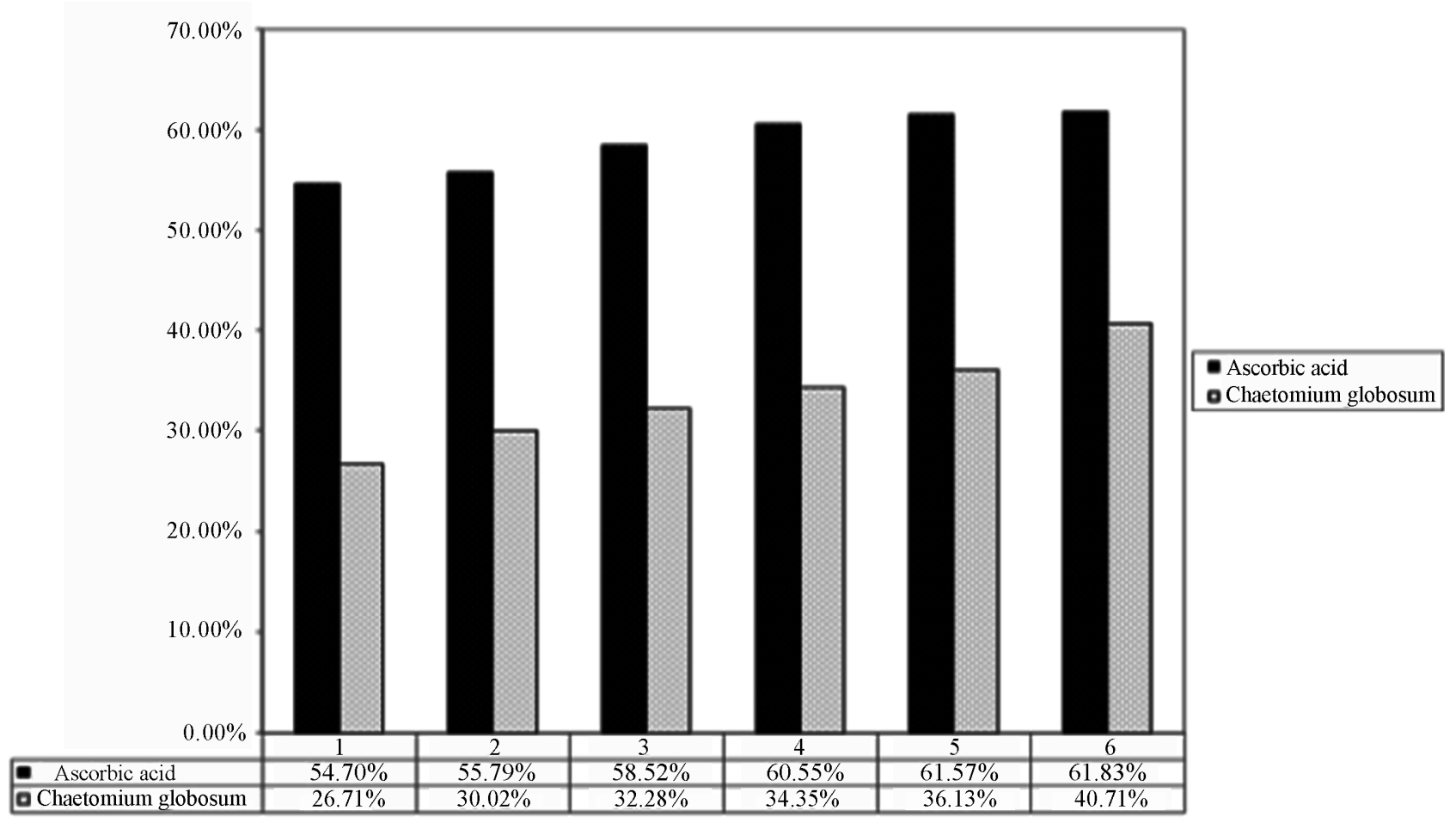

Figure 11. Show the DPPH inhibition assay by $C$. globosum.

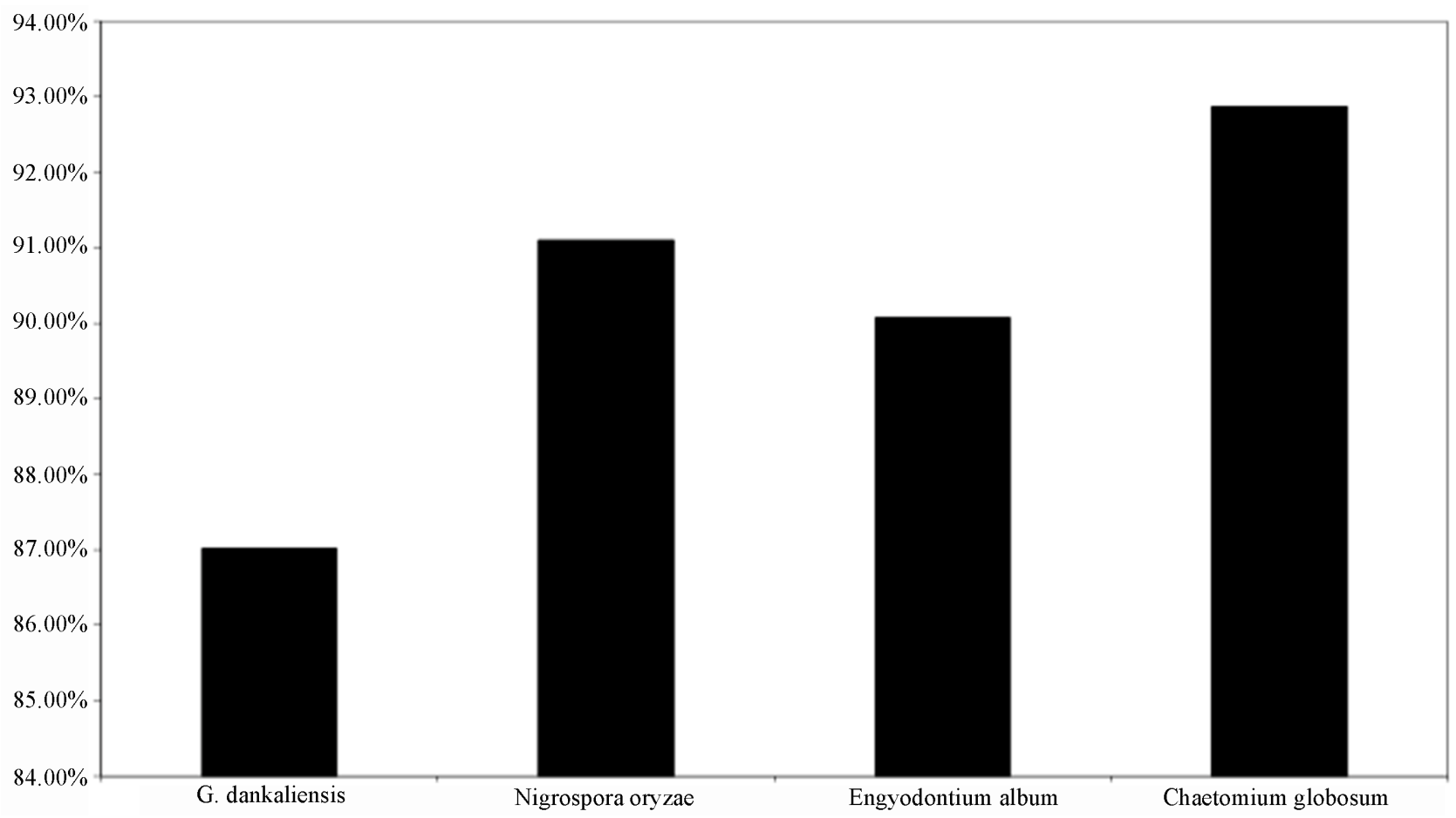

Figure 12. The inhibition of lipid preoxidation of different fungal extracts.

are oxidized by radicals, resulting in a more stable, less-reactive radical. In other words, flavonoids stabilize the reactive oxygen species by reacting with the reactive compound of the radical. Because of the high reactivity of the hydroxyl group of the flavonoids, radicals are made inactive, according to the following equation; Flavonoid $(\mathrm{OH})+\mathrm{R} \bullet>$ flavonoid $(\mathrm{O} \bullet)+\mathrm{RH}[53]$, and that can explain the antioxidant capacity of our extracts, due 


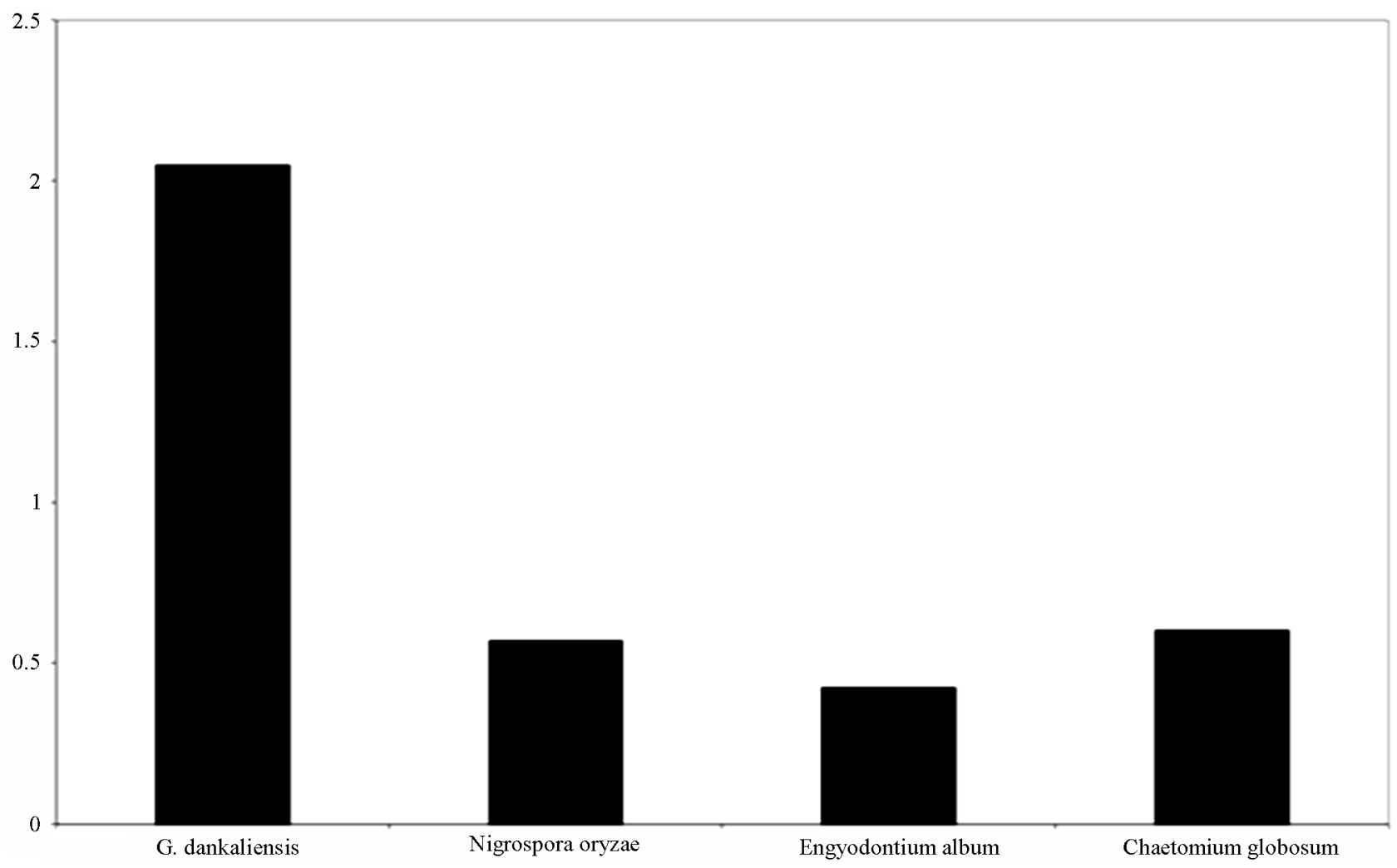

Figure 13. Total phenolic content in different fungal extract.

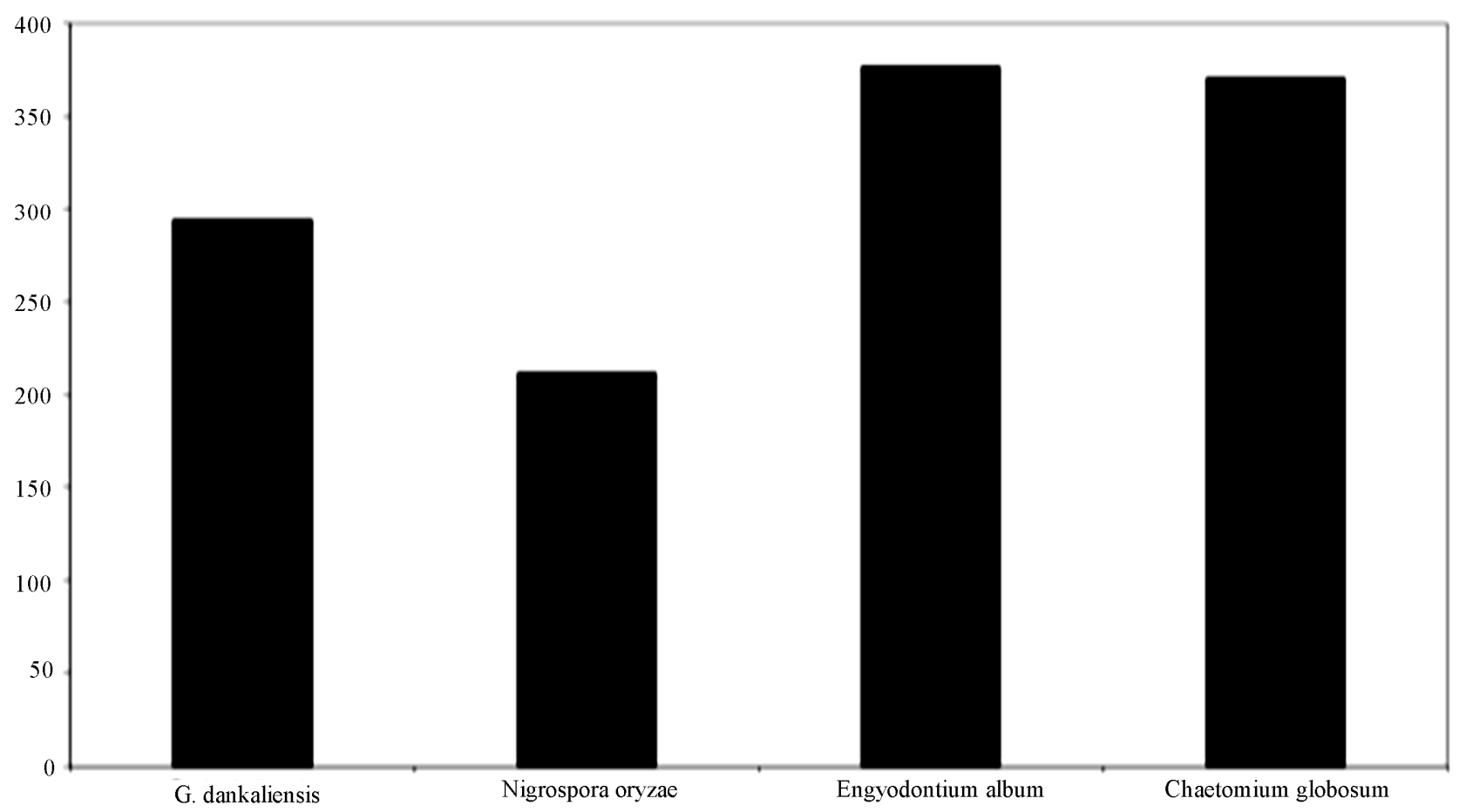

Figure 14. Total flavnoids content different fungal extracts.

to their flavnoids content. also the scavenger of nitric oxide (anti-inflammatory effect) show in Figures 15-18 can be attributed to the total phenolic and flavnoids con- tent, as The same in case of scavenger of nitric oxide as nitric oxide reacts with free radicals, thereby producing the highly damaging peroxynitrite. Nitric oxide injury 


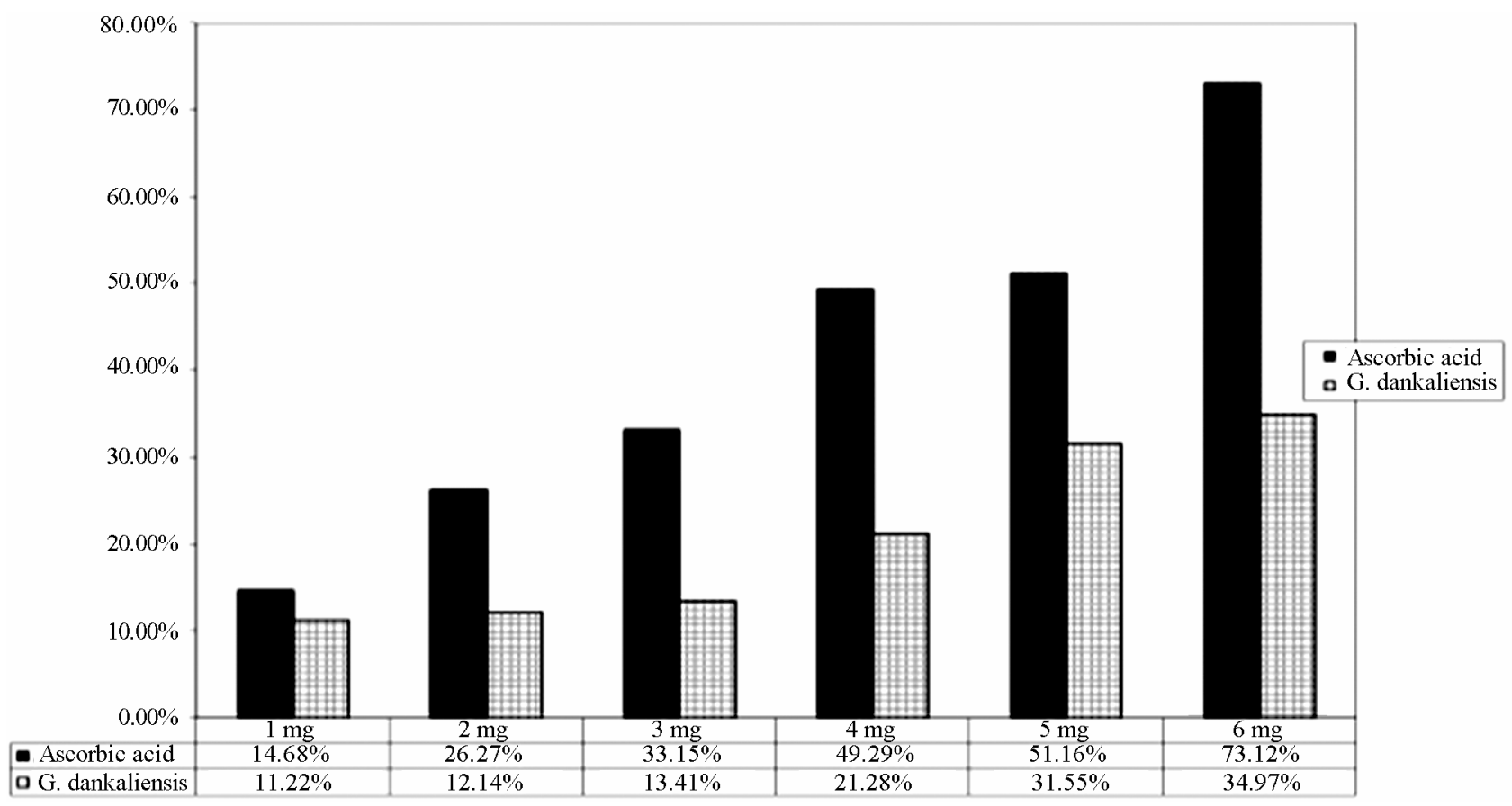

Figure 15. Show the inhibition of NO by G. dankaliensis fungal extract.

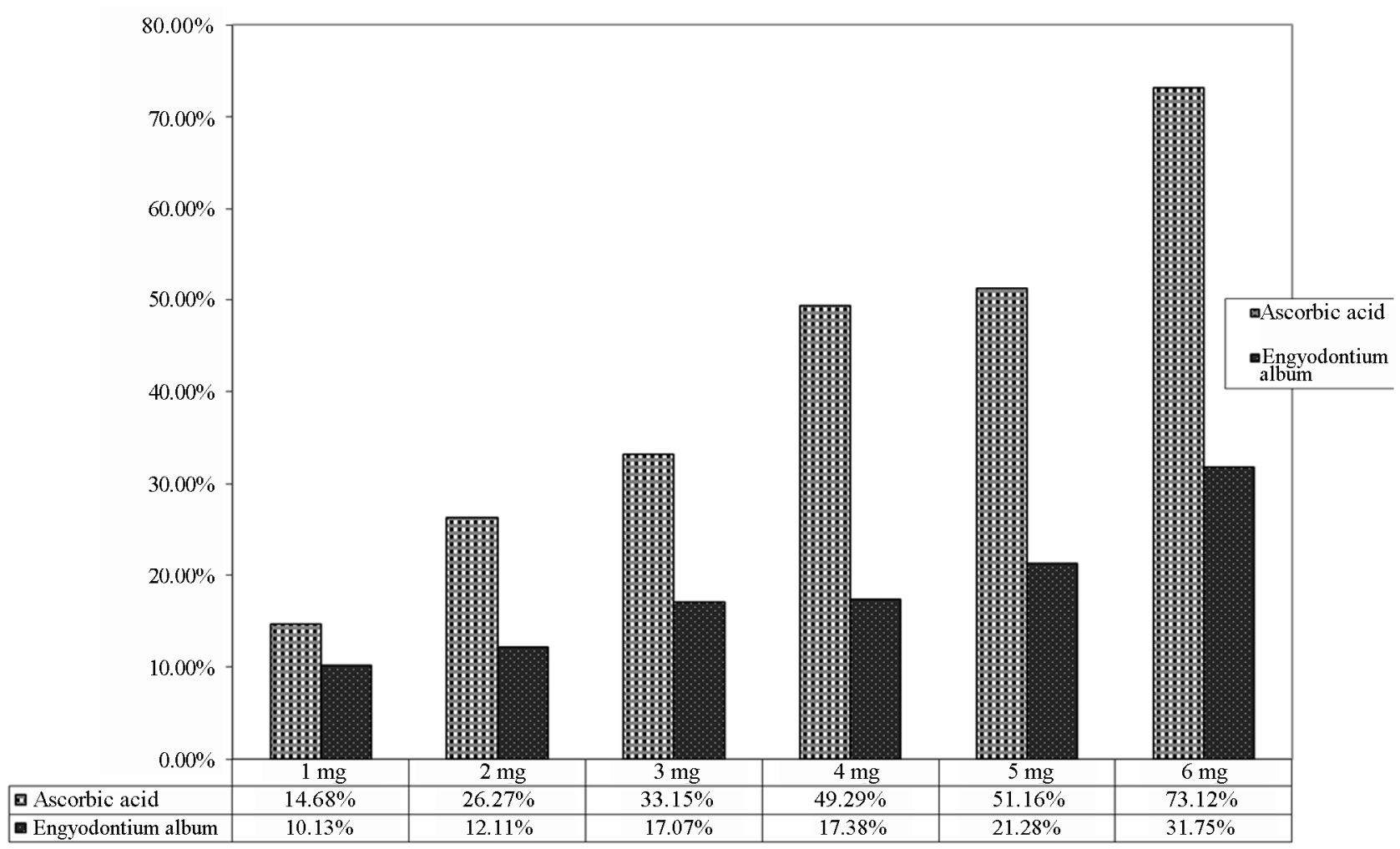

Figure 16. Show the inhibition of NO by Nigrospora oryzae fungal extract.

takes place for the most part through the peroxynitrite route because peroxynitrite can directly oxidize LDLs, resulting in irreversible damage to the cell membrane. When flavonoids are used as antioxidants, free radicals are scavenged and therefore can no longer react with nitric oxide, resulting in less damage [54]. Interestingly, nitric oxide can be viewed as a radical itself, and it is was reported that nitric oxide molecules are directly scav- 


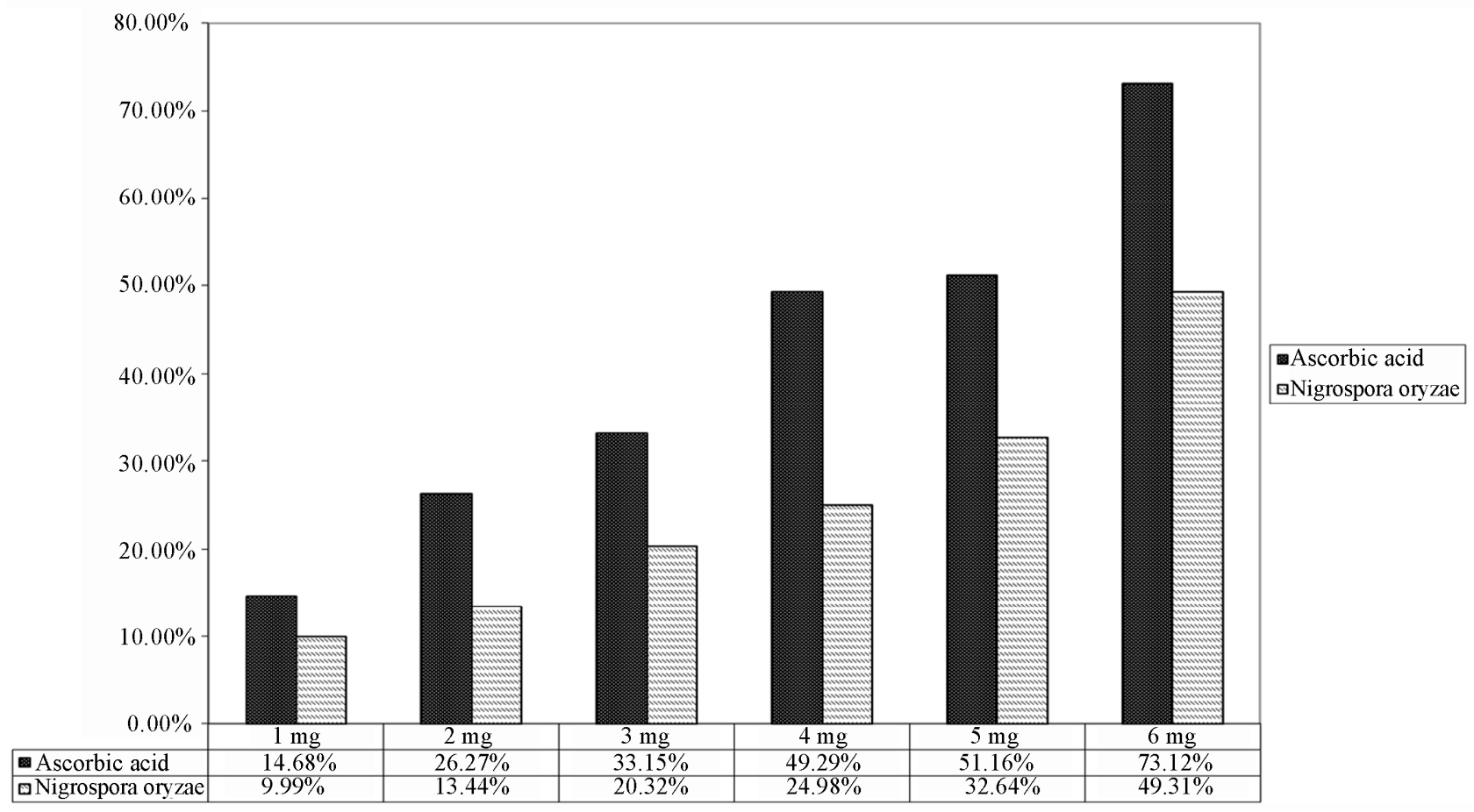

Figure 17. Show the inhibition of NO by Engyodontium album fungal extract.

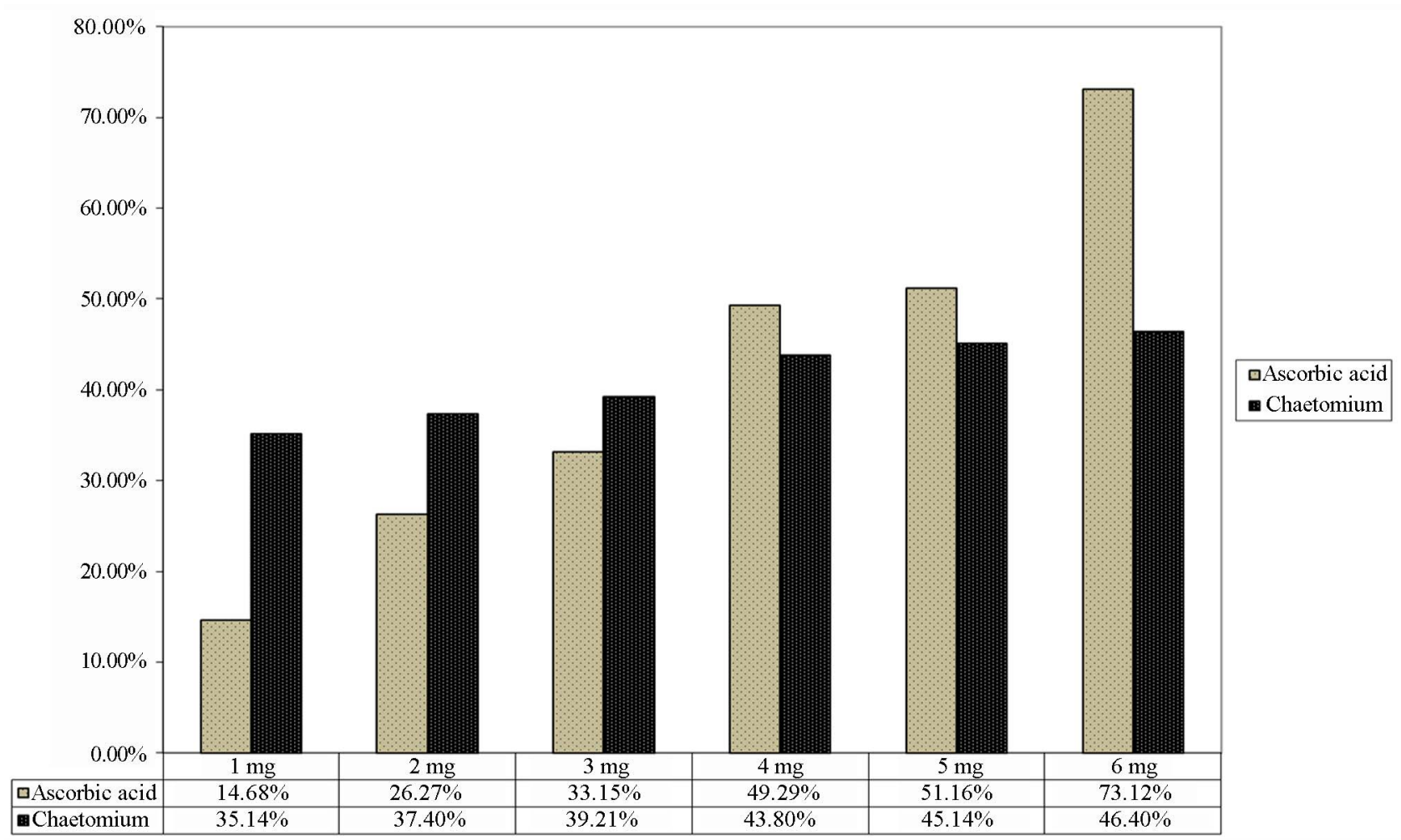

Figure 18. Show the inhibition of NO by $C$. globosum fungal extract.

enged by flavonoids [55].

Although we can attributed the antioxidant activity and anti-inflammatory effect of different fungal extracts, this may be due to the marine chemodiversty, which is also heightened by their composition of sea water itself where, concentration of halides in sea water of $1900 \mathrm{mg} / \mathrm{L}$ 


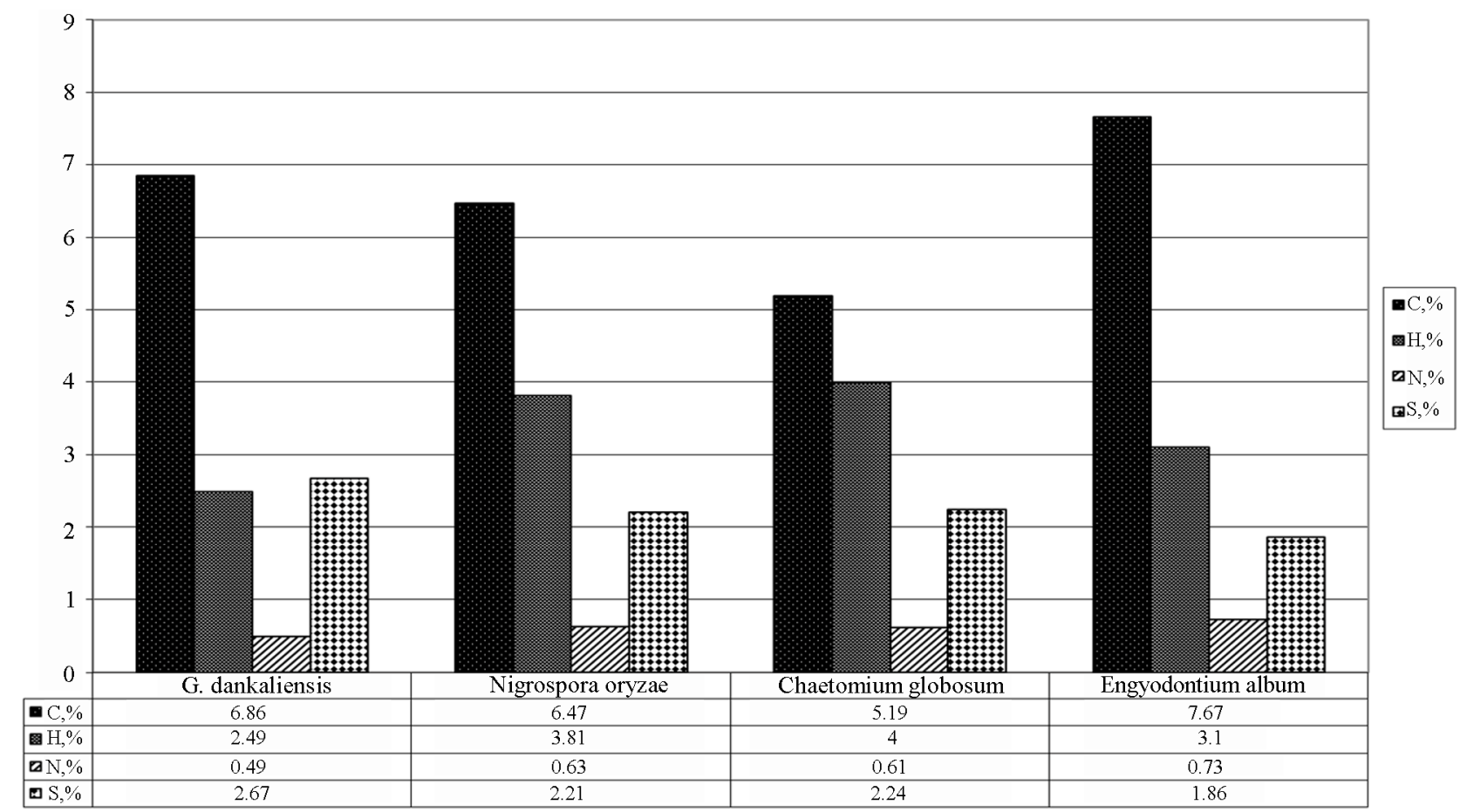

Figure 19. Show \% of C, N, H, S in different fungal extract where C: carbon, H: hydrogen, N: nitrogen, S: sulphur.

$\mathrm{Cl}^{-}, 65 \mathrm{mg} / \mathrm{L} \mathrm{Br}^{-}, 5 \times 10^{-4}$ and $\mathrm{I} / \mathrm{IO}^{3-}$ are reflected by the number of compounds incorporating these elements and sulfated compounds can accounted for by the relatively high concentration of sulfur, $2700 \mathrm{mg} / \mathrm{L}$ seawater, and that confirmed in our study as shown in Figure 19 [56] .

\section{Conclusion}

In conclusion, we observed beneficial influence of investigated fungal extracts as antioxidants and anti-inflammatory. We could assume that this extracts possess antiinflammatory property due to their proven antioxidant, free radical scavenging properties, and their high sulfur content. However, further investigations on the structures, of the bioactivity, in the four different fungal extracts, as well as elucidation of compounds responsible for such activities and their effect on different antioxidant application should be carryied on.

\section{REFERENCES}

[1] U. Bandhopadhyay, D. Das and R. K. Banerjee, "Reactive Oxygen Species: Oxidative Damage and Pathogenesis," Current Science, Vol. 77, No. 5, 1999, pp. 658-666.

[2] T. Finkel and N. J. Holbrook, "Oxidants, Oxidative Stress and Biology of Ageing," Nature, Vol. 408, No. 6809, 2000, pp. 239-247. doi:10.1038/35041687

[3] V. Aher, A. Wahi, A. M. Pawdey and A. Sonawane, "Antioxidants as Immunomodulator: An Expanding Research Avenue," International Journal of Current Pharmaceutical Research, Vol. 3, No. 1, 2011, pp. 8-10.
[4] G. A. Blaise, D. Gauvin, M. Gangal, et al., "Nitric Oxide, Cell Signaling and Cell Death," Toxicology, Vol. 208, No. 2, 2005, pp. 177-192. doi:10.1016/j.tox.2004.11.032

[5] C. Bogdan, "Nitric Oxide and Regulation of Gene Expression," Trends in Cell Biology, Vol. 11, No. 2, 2001, pp. 66-75.

[6] H. C. Grice, "Safety Evaluation of Butylated Hydroxyanisole from the Perspective of Effects on Forestomach and Oesophageal Squamous Epithelium," Food and Chemical Toxicology, Vol. 26, No. 8, 1988, pp. 717-723. doi:10.1016/0278-6915(88)90072-5

[7] H. M. Qi, Q. B. Zhang, T. T. Zhao, R. Chenc, H. Zhang, X. Z. Niu and Z. E. Li, "Antioxidant Activity of Different Sulfate Content Derivatives of Polysaccharide Extracted from Ulva Pertusa (Chlorophyta) in Vitro," International Journal of Biological Macromolecules, Vol. 37, No. 4, 2005, pp. 195-199.

doi:10.1016/j.ijbiomac.2005.10.008

[8] R. Scherer and H. Teixeira, "Antioxidant Activity Index (AAI) by the 2,2-Diphenyl-1-picrylhydrazyl Method," Food Chemistry, Vol. 112, No. 3, 2009, pp. 654-658. doi:10.1016/j.foodchem.2008.06.026

[9] H.-H. Sun, W.-J. Mao, Y. Chen, S.-D. Guo, H.-Y. Li, X.-H. Qi, Y.-L. Chen and J. Xu, "Isolation, Chemical Characteristics and Antioxidant Properties of the Polysaccharides from Marine Fungus Penicillium sp. F23-2," Carbohydrate Polymers, Vol. 78, No. 1, 4, 2009, pp. 117 124.

[10] D. L. Lefkowitz, M. P. Gelderman, S. R. Fuhrmann, et al., "Neutrophilic Myeloperoxidase-Macrophage Interactions Perpetuate Chronic Inflammation Associated with Experimental Arthritis," Clinical Immunology, Vol. 91, No. 2, 
1999, pp. 145-155. doi:10.1006/clim.1999.4696

[11] N. Hogg, "Free Radicals in Disease," Seminar in Reproductive Endocrinology, Vol. 16, No. 4, 1998, pp. 241248. doi:10.1055/s-2007-1016284

[12] M. Miller, S. Wilson, M. Dorf, H. Seuanez, S. O’Brien and M. Krangel "Sequence and Chromosomal Location of the 1-309 Gene: Relationship to Genes Encoding a Family of Inflammatory Cytokines," The Journal of Immunology, Vol. 145, 1990, pp. 2737-2744.

[13] T. Yoshikawa and Y. Naito, "The Role of Neutrophils and Inflammation in Gastric Mucosal Injury," Free Radical Research, Vol. 33, No. 6, 2000, pp. 785-794. doi:10.1080/10715760000301301

[14] P. Valentao, E. Fernandes, F. Carvalho, P. B. Andrade, R. M. Seabra and M. L. Bastos, "Studies on the Antioxidant Activity of Lippa Citriodoru Infusion Scavenging Effect on Superoxide Radical, Hydroxyl Radical and Hypochlorousacid," Biological \& Pharmaceutical Bulletin, Vol. 25, No. 10, 2002, pp. 1324-13227.

[15] O. I. Aruoma, "Characterization of Drugs as Antioxidant Prophylactics," Free Radical Biology and Medicine, Vol. 20, No. 5, 1996, pp. 675-705. doi:10.1016/0891-5849(95)02110-8

[16] G. R. Schinella, H. A. Tournier, J. M. Prieto, P. M. de Buschiazzo and J. L. Rios, "Antioxidant Activity of AntiInflammatoryplant Extracts," Life Sciences, Vol. 70, No. 9, 2002, pp. 1023-1033. doi:10.1016/S0024-3205(01)01482-5

[17] F. Liu and T. B. Ng, "Antioxidative and Free Radical Scavenging Activities of Selected Medicinal Herbs," Life Sciences, Vol. 66, No. 8, 2000, pp. 725-735. doi:10.1016/S0024-3205(99)00643-8

[18] G. M. Konig, S. Kehraus, S. F. Seiber, A. Abdel-Lateff and D. Muller, "Natural Products from Marine Organisms and Their Associated Microbes," ChemBioChem, Vol. 7, No. 2, 2006, pp. 229-238. doi:10.1002/cbic.200500087

[19] W. Fenical, "Chemical Studies of Marine Bacteria: Developing a New Resource," Chemical Reviews, Vol. 93, No. 2, 1993, pp. 1673-1683. doi:10.1021/cr00021a001

[20] M. Belcastro, T. Marino, N. Russo and M. Toscano, "Structural and Electronic Characterization of Antioxidants from Marine Organisms, Theoretical Chemistry Accounts: Theory, Computation, and Modeling," Theoretica Chimica Acta, Vol. 115, No. 5, 2006, pp. 361-369. doi:10.1007/s00214-006-0077-5

[21] B. Halliwell, "Antioxidants in Human Health and Disease," Annual Review of Nutrition, Vol. 16, No. 1, 1996, pp. 33-50. doi:10.1146/annurev.nu.16.070196.000341

[22] S. Nandita and P. S. Rajini, "Free Radical Scavenging Activity of an Aqueous Extract of Potato Peel," Food Chemistry, Vol. 85, No. 4, 2004, pp. 611-616. doi:10.1016/j.foodchem.2003.07.003

[23] D. H. Luo, "Identification of Structure and Antioxidant Activity of a Fraction of Polysaccharide Purified from Dioscorea nipponica Makino," Carbohydrate Polymers, Vol. 71, No. 4, 2008, pp. 544-549. doi:10.1016/i.carbpol.2007.06.023

[24] K. B. Raper and C. Thorn, "A Manual of the Penicillia,"
Williams and Wilkins Co., Baltimore, 1949.

[25] J. I. Pitt, "The Genus Penicillium and Its Teleomorphic States Eupenicillium and Talaromyces," Academic Press, Waltham, 1980.

[26] K. B. Raper and D. I. Fennell, "The Genus Aspergillus," Williams and Wilkins Co., Baltimore, 1965.

[27] M. B. Ellis, "Dematiaceoua Hyphomycetes," Commonwealth Mycological Institute, Kew, Surrey, 1971.

[28] M. B. Ellis, "More Dematiaceous Hyphomycetes," Commonwealth Mycological Institute, Kew, Surrey, 1976.

[29] C. Booth, "Fusarium, Laboratory Guide to the Identification of the Major Species," Commonwealth Mycological Institute, Kew, Surrey, 1971.

[30] A. Avon, "Genera of Fungi Sporulating in Pure Culture," $3^{\text {rd }}$ Edition, J. Cramer, Vaduz, 1981.

[31] K. H. Domsch, W. Gams and T.-H. Anderson, "Compendium of Soil Fungi," Academic Press, Waltham, 1980.

[32] T. Watanabe, "Pictorial Atlas of Soil and Seed Fungi. Morphologies of Cultured Fungi and Key to Species," 2nd Edition, CRC Press, Boca Raton, 2002. doi:10.1201/9781420040821

[33] J. A. von Arx, J. Guarro and M. J. Figueras, "Mycosphere the Ascomycete Genus Chaetomium," Beihefte zur Nova Hedwigia, Vol. 84, 1986, pp. 1-162.

[34] P. F. Cannon, "A Revision of Achaetomium, Achaetomiella and Subramaniula, and Some Similar Species of Chaetomium," Transactions of British Mycological Society, Vol. 87, No. 1, 1986, pp. 45-76. doi:10.1201/9781420040821.ch1

[35] P. Kirk, P. F. Cannon, D. W. Minter and J. A. Stalpers, "Ainsworth and Bisby's Dictionary of the Fungi," 10th Edition, CAB International, Wallingford, 2008. doi:10.1016/S0007-1536(86)80004-3

[36] M. S. Taga, E. E. Miller, D. E. Pratt, "China Seeds as a Source of Natural Lipid Antioxidant," Journal of the American Oil Chemists' Society, Vol. 61, 1984, pp. 928931.

[37] Z. Jia, M. Tang and J. Wu, "The Determination of Flavonoid Contents in Mulberry and Their Scavenging Effects on Superoxide Radicals," Food Chemistry, Vol. 64, No. 4, 1999, pp. 555-559. doi:10.1016/S0308-8146(98)00102-2

[38] M. S. Blois, "Antioxidant Determinations by the Use of a Stable Free Radical," Nature, Vol. 181, 1958, pp. 11991200. doi:10.1038/1811199a0

[39] R. Amarowicz, M. Naczk and F. Shahidi, "Antioxidant Activity of Various Fractions of Non-Tannin Phenolics of Canola Hulls," Journal of Agricultural and Food Chemistry, Vol. 48, No. 7, 2000, pp. 2755-2759. doi:10.1021/jf9911601

[40] B. Wallin, B. Rosengren, H. G. Shertzer and G. Camejo, "Lipoprotein Oxidation and Measurement of Thiobarbituric Acid Reacting Substances Formation in a Single Microtiter Plate: Its Use for Evaluation of Antioxidants," Analytical Biochemistry, Vol. 208, No. 1, 1993, pp. 1015. doi:10.1006/abio.1993.1002

[41] F. Xie, A. Yu, D. Hou, H. Liu, L. Ding and S. Zhang, 
"Rapid and Sensitive Analysis of Eight Polyphenols in Tobacco by Rapid Resolution Liquid Chromatogarphy," American Journal of Analytical Chemistry, Vol. 2, No. 8, 2011, pp. 929-933. doi:10.4236/ajac.2011.28107

[42] B. M. Silva, P. B. Andrade, P. Valentãoo, F. Ferreres, R. M. Seabra and M. A. Ferreira, "Quince (Cydonia oblonga Miller) Fruit (Pulp, Peel, and Seed) and Jam: Antioxidant Activity," Journal of Agricultural and Food Chemistry, Vol. 52, No. 15, 2004, pp. 4705-4712. doi:10.1021/jf040057v

[43] R. Pulido, L. Bravo and F. Saura-Calixto, "Antioxidant Activity of Dietary," 2000.

[44] T. H. Tseng, E. S. Kao, C. Y. Chu, F. P. Chou, H. W. Lin and C. J. Wang, "Protective Effects of Dried Flower Extracts of Hibiscus sabdariffa L. against Oxidative Stress in Rat Primary Hepatocytes," Food and Chemical Toxicology, Vol. 35, No. 12, 1997, pp. 1159-1164. doi:10.1016/S0278-6915(97)85468-3

[45] I. Zupko, J. Hohmann, D. Redei, G. Falkay, G. Janicsak and I. Mathe, "Antioxidant Activity of Leaves of Salvia Species in Enzyme-Dependent and Enzyme-Independent Systems of Lipid Peroxidation and Their Phenolic Constituents," Planta Medica, Vol. 67, No. 4, 2001, pp. 366368. doi:10.1055/s-2001-14327

[46] B. B. Li, B. Smith and M. M. Hossain, "Extraction of Phenolics from Citrus Peels I. Solvent Extraction Method," Separation and Purification Technology, Vol. 48, No. 2, 2006, pp. 182-188. doi:10.1016/j.seppur.2005.07.005

[47] P. D. Duh, Y. Y. Tu and G. C. Yen, "Antioxidant Activity of Water Extract of Harng Jyur (Chrysanthemum morifolium Ramat)," LWT-Food Science and Technology, Vol. 32, No. 5, 1999, pp. 269-277.

[48] A. Scalbert, C. Manach, C. Morand and C. Remesy, "Dietary Polyphenols and the Prevention of Disease," Critical Reviews in Food and Nutrition, Vol. 45, No. 4, 2005, pp. 287-306. doi:10.1080/1040869059096

[49] W. C. Dunlap and Y. Yamamoto, "Small-Molecule An- tioxidants in Marine Organisms: Antioxidant Activity of Mycosporine-Glycine," Comparative Biochemistry and Physiology Part B, Vol. 112, No. 1, 1995, pp. 105-114. doi:10.1016/0305-0491(95)00086-N

[50] Y. Yamamoto, Y. Yukiko Kobayashi and H. Matsumoto, "Lipid Peroxidation Is an Early Symptom Triggered by Aluminum, but Not the Primary Cause of Elongation Inhibition in Pea Roots," Plant Physiology, Vol. 125, No. 1, 2001, pp. 199-208. doi:10.1104/pp.125.1.199

[51] M. J. Abad, L. M. Bedoya and P. Bermejo, "Natural Marine Anti-Inflammatory Products," Mini-Reviews in Medicinal Chemistry, Vol. 8, No. 8, 2008, pp. 740-754. doi: $10.2174 / 138955708784912148$

[52] M. Nakamura, T. Ando, A. Masataka, K. Kumagai and Y. Endo, "Contrast between Effects of Aminobisphosphonates and Non-Aminobisphosphonates on Collagen-Induced Arthritis in Mice," British Journal of Pharmacology, Vol. 119, No. 2, 1996, pp. 205-212. doi:10.1111/j.1476-5381.1996.tb15972.x

[53] L. G. Korkina and I. B. Afanas'Ev, "Antioxidant and Chelating Properties of Flavonoids," Advances in Pharmacology, Vol. 38, 1997, pp. 151-163. doi:10.1016/S1054-3589(08)60983-7

[54] Z. Shutenko, Y. Henry, E. Pinard, et al., "Influence of the Antioxidant Quercetin in Vivo on the Level of Nitric Oxide Determined by Electron Paramagnetic Resonance in Rat Brain during Global Ischemia and Reperfusion," Biochemical Pharmacology, Vol. 57, No. 2, 1999, pp. 199-208. doi:10.1016/S0006-2952(98)00296-2

[55] S. A. Van Acker, D. J. Van-den Berg, M. N. J. L. Tromp, G. R. Haenen, W. J. van der Vijgh and A. Bast, "Flavonoids as Scavengers of Nitric Oxide Radical," Biochemical and Biophysical Research Communications, Vol. 214, No. 3, 1995, pp. 755-759. doi:10.1006/bbrc.1995.2350

[56] W. Fenical, "Natural Products Chemistry in the Marine Environment," Science, Vol. 215, No. 4535, 1982, pp. 923-928. doi:10.1126/science.215.4535.923 